\title{
Effect of the Enantiomeric Ratio of Eutectics on the Results and Products of the Reactions Proceeding with the Participation of Enantiomers and Enantiomeric Mixtures
}

\author{
Emese Pálovics *, Dorottya Fruzsina Bánhegyi@ and Elemér Fogassy \\ Department of Organic Chemistry and Technology, Budapest University of Technology and Economics, \\ 1521 Budapest, Hungary; banhegyidorottyafruzsina@gmail.com (D.F.B.); efogassy@mail.bme.hu (E.F.) \\ * Correspondence: epalo@mail.bme.hu; Tel.: +36-1-4632101
}

Received: 3 August 2020; Accepted: 14 September 2020; Published: 21 September 2020

\begin{abstract}
This perspective is focused on the main parameters determining the results of crystallization of enantiomers or enantiomeric mixtures. It was shown that the ratio of supramolecular and helical associations depends on the eutectic composition of the corresponding enantiomeric mixture. The $\mathrm{M}$ and $\mathrm{P}$ ratios together with the self-disproportionation (SDE) of enantiomers define the reaction of the racemic compound with the resolving agent. Eventually, each chiral molecule reacts with at least two conformers with different degrees of $\mathrm{M}$ and $\mathrm{P}$ helicity. The combined effect of the configuration, charge distribution, constituent atoms, bonds, flexibility, and asymmetry of the molecules influencing their behavior was also summarized.
\end{abstract}

Keywords: chiral molecules; enantiomeric separation; self-disproportionation of enantiomers; supramolecular associations; helical structure; eutectic composition

\section{Introduction}

The preparation of asymmetric (chiral) compounds (enantiomers) is one of the main goals of research, industry and medicine. The preparation of a given enantiomer is possible in several ways, for example by selective synthesis, which requires the separation of the chiral catalyst or the enantiomers of the racemic compound, and in which case a resolving agent (like a chiral catalyst) may be required. In this case, we are confronted with the non-linear behavior [1] as well as the self-organization [2] of chiral compounds and their $\mathrm{M}$ and $\mathrm{P}$ helicity [3].

In our work $[4,5]$ we proved that the result of non-linear processes of enantiomers, enantiomeric mixtures, and mixtures of diastereomers, taking into account the solvent and the crystallization time, depends on the eutectic ratio of the enantiomeric mixtures of the participating chiral compounds. By this eutectic composition, the enantiomeric ratio $\left(\mathrm{ee}_{\mathrm{Eu}}\right)$ corresponding to the eutectic points of the "binary melting point phase diagrams" of the enantiomeric mixtures (Figure 1) is meant. 
A

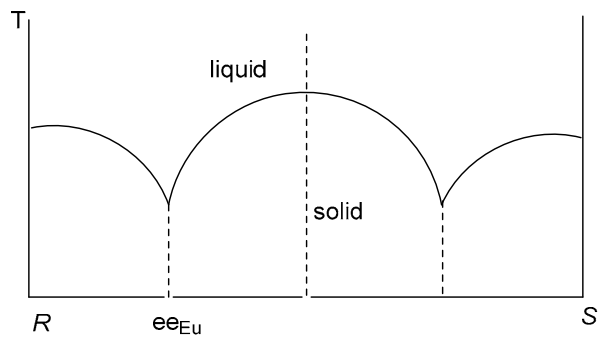

B

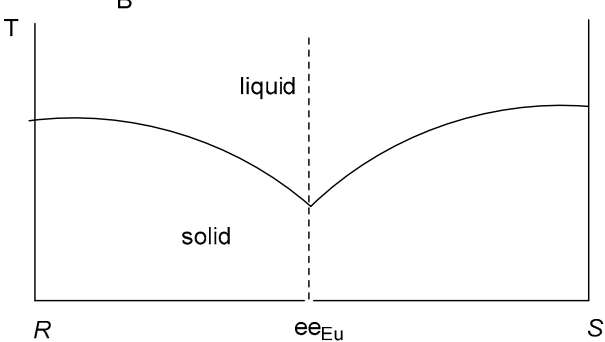

Figure 1. Melting point phase diagrams of a racemate forming (A) and of a conglomerate forming enantiomeric mixture (B).

Binary melting point phase diagrams were described by Roseboom [6] based on the behavior of enantiomeric mixtures. Important evidence was that the distribution of enantiomeric mixtures between two (solid, liquid) phases is non-linear. The racemate forming enantiomeric mixtures [7] are estimated to be about $80 \%$ of enantiomeric mixtures. Besides ee $\mathrm{Eu}_{\mathrm{u}}$, the melting point values of the single enantiomers and of the racemic composition are of prominent importance.

In general, these preferred values also appear on the solubility ternary phase diagrams when crystallizing from solutions of mixtures of chiral compounds. For practical reasons, the result of crystallization (ee) from a solution of a given concentration of enantiomeric mixture is plotted against the starting enantiomeric mixture composition $\left(\mathrm{ee}_{0}\right)$ (Figure 2).

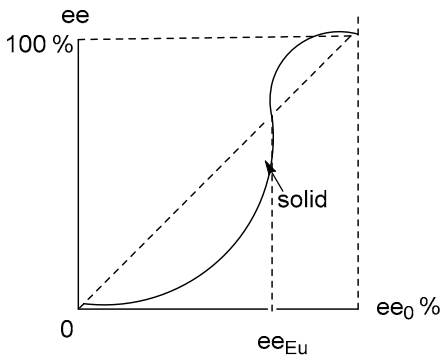

(A)

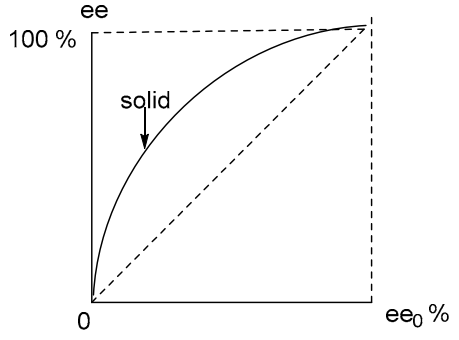

(B)

Figure 2. The ee ${ }_{0}$-ee separation diagrams of a racemate (A) and of a conglomerate (B) enantiomeric mixture of a given concentration.

\section{Separation of Non-Racemic Enantiomeric Mixtures-Eutectic Composition}

The ee $e_{0}$-ee diagrams also show the $e_{\mathrm{Eu}}$ (at the intersection of the $45^{\circ}$ line). From the $e_{0}$ precipitates the portion close to the racemic ratio of the enantiomeric mixture below $e_{\mathrm{Eu}}$, while above it the enantiomeric excess of the mixture. In essence, the latter is also the case for conglomerate forming mixtures. Thus, a single enantiomer can only be obtained from a mixture of enantiomeric purity greater than $\mathrm{ee}_{\mathrm{Eu}}$, e.g., by crystallization. However, if the eutectic point of the enantiomeric mixture is high, a lower $e_{\mathrm{Eu}}$ can be achieved with its derivative formed with an achiral compound. For example, in the case of ibuprofen, with a mixture of sodium salts with the same ratio, the single enantiomeric separation [8] can start from a lower $\mathrm{e}_{\mathrm{Eu}}$ composition (Figure 3). 


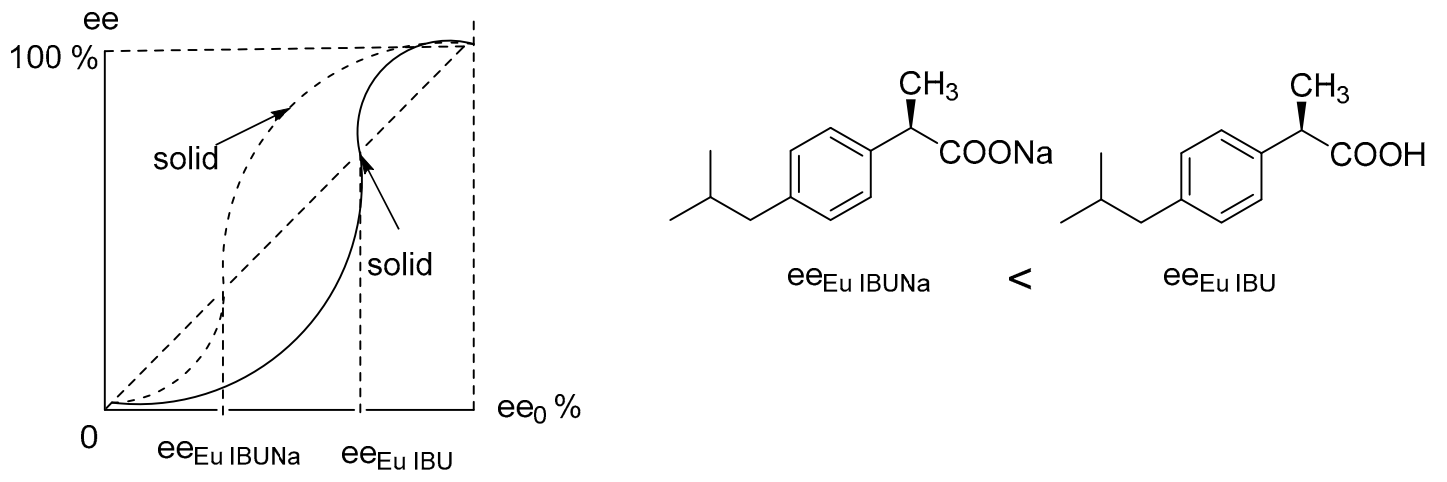

Figure 3. Phase diagram (ee $e^{-e e)}$ of the enantiomeric mixture of ibuprofen and ibuprofen-Na salt.

In the first separation of enantiomers, Pasteur used the fractional crystallization of the conglomerate forming sodium ammonium salt of tartaric acid (racemic tartaric acid) [9] instead of the direct separation of the racemate forming tartaric acid enantiomers.

Klussmann et al. showed that in case of amino acid enantiomeric mixtures, besides the application of additives, e.g., crystallizing from a solvent using dicarboxylic acids, a eutectic different from the eutectic composition on the binary melting point phase diagram appears on the $e_{0}$-ee diagram [10].

Girad found that starting from prochiral compounds, the enantiomeric composition of the resulting compounds varies depending on the composition of the chiral catalyst enantiomers [1].

Klussmann et al. demonstrated that in the case of an aldol reaction there is a relationship between the eutectic composition of the amino acid used as a catalyst and the composition of the product [11]. For example, in the presence of proline ( $50 \%$ eutectic composition), the aldol reaction results in $50 \%$ enantiomeric purity, the same result was obtained also in the presence of less than $50 \%$ pure, or even purer proline enantiomeric mixtures. Thus, the $e_{\mathrm{Eu}}$ composition of the chiral catalyst can determine the enantiomeric purity of the product (Figure 4).

prochiral compound

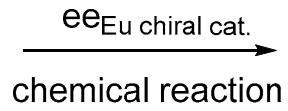

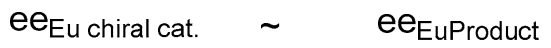

Figure 4. The effect of the chiral catalyst on the enantiomeric purity of the product.

Substantially after the completion of the reaction, the reaction mixture contains the two non-racemic mixtures of the enantiomers in the same proportion as the eutectic composition of the catalyst, and the chiral catalyst.

However, the distribution of non-racemic enantiomeric mixtures [12] between two phases is also determined by their own eutectic composition.

\section{The Effect of the Eutectic Composition of the Racemic Compound on the Diastereomeric Separation}

When a racemic (or non-racemic) enantiomeric mixture is reacted with a single enantiomer of related molecular structure but of opposite character (as a resolving agent), the composition of the enantiomeric mixture that can be separated from the precipitating diastereomeric salt (which can be filtered from the solution) is the same as its own eutectic composition (ee $\mathrm{Dia}_{\mathrm{Dia}}-\mathrm{ee}_{\mathrm{EuRac}}$ ) [4].

For example, after dissolving racemic fluor-acetyl-phenylglicine (FAPhG) and (R)-methylphenylglicine $((R)-\mathrm{MPhG})$ in water, the $(S, R)$-diastereomer could be separated by crystallization 
(Figure 5), where the ee Dia $_{\text {was }}$ circa $86.3 \%$, which is in good agreement with the eutectic composition of the racemic compound (ee $\mathrm{EuRac}_{28} \sim 8 \%$ ).

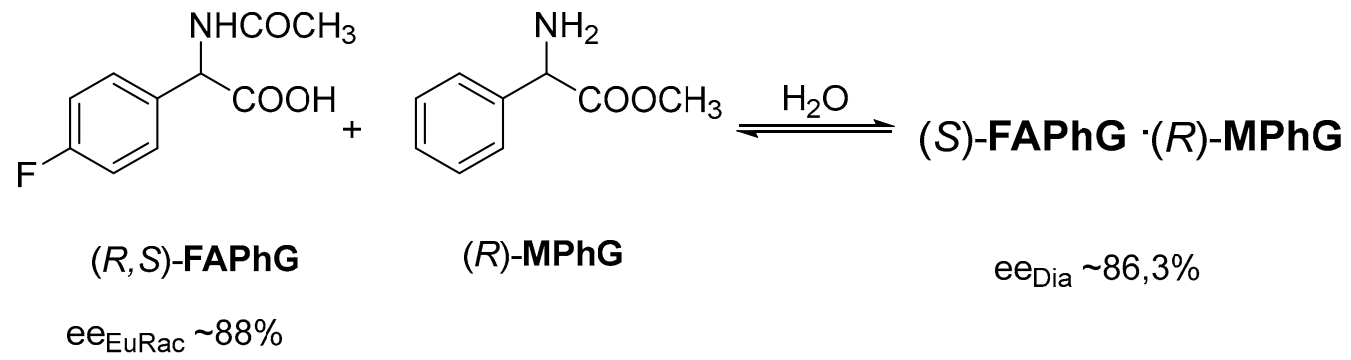

Figure 5. Diastereomic salt formation of $(R, S)-\mathrm{FAPhG}$ with $(R)-\mathrm{MPhG}$ resolving agent-similar eutectic composition of racemic and diastereomeric compound.

When related structured resolving agents were used, the mean of the eutectic compositions of the examined racemic compounds $(85.3 \%)$ was in good agreement with the mean of the compositions of the enantiomeric mixtures isolated from the corresponding diastereomeric salt (85.9\%) [4].

Even if there is no molecular structural relationship between the racemic compound and the resolving agent, the eutectic composition of the racemic compound may still be decisive for the composition of the diastereomer.

For example, the eutectic composition of the Flumequine intermediate (FTHQ) for the racemic base corresponds well with the composition of the enantiomeric mixture isolated from the diastereomer obtained with the $(R, R)$-DPTA resolving agent (Figure 6) [13].<smiles>CC1CCc2cc(F)ccc2N1</smiles>

$(R, S)-F T H Q$

$\mathrm{ee}_{\mathrm{EuRac}}=40 \%$<smiles>[R]C(=O)C(OC(=O)c1ccc(C)cc1)C(OC(=O)c1ccc(C)cc1)C(=O)O</smiles>

0.5 eq. $(R, R)$-DPTA

$$
\text { ee }_{\text {EuRes }}=90 \%
$$

$(R)-\mathrm{FTHQ}-(R, R)$-DPTA

$5 \min$.

Figure 6. Diastereomeric salt formation of $(R, S)$-FTHQ with half equivalent $(R, R)$-DPTA.

If the eutectic compositions of the racemic compound were averaged during the 45 resolutions developed by our group (ee Euaverage $\sim 73 \%$ ), and the enantiomeric compositions separated from the crystalline diastereomeric salt were also averaged (ee Diaaverage $\sim 78 \%$ ), a good agreement could be obtained, so ee $e_{\text {Dia }} \sim$ ee $_{\text {EuResAg }}[14]$.

\section{The Effect of the Resolving Agent (Enantiomeric Mixture) on the Diastereomeric Separation}

Since the eutectic composition of the enantiomeric mixtures of the racemic resolving agent can also determine the ee $e_{\text {Dia }}$ value when separated with the appropriate unrelated molecular structured resolving agent, the average of the resolving agents (ee $\mathrm{EuResAg}_{\mathrm{R}}$ ) used in previous resolutions was determined (ee EuResAgaverage $\sim 78 \%$ ) that also showed good accordance (ee Diaaverage $\sim 80 \%$ ). Thus, the enantiomeric composition of the crystalline precipitating diastereomeric salts can also be determined by the eutectic composition of the enantiomeric mixtures of the single enantiomeric resolving agent, i.e., $e_{\text {Dia }} \sim$ ee $_{\text {Rac }}$ or $\sim$ ee $_{\text {EuResAg. }}$.

$\mathrm{Ee}_{\text {Dia }} \sim \mathrm{ee}_{\text {Rac }}$ is understandable, since both enantiomers are present during crystallization, thus the effect of the eutectic composition prevails. 
The chiral (enantiomeric mixture) catalyst may also enforce (ee $\mathrm{EuKat}_{\text {at }}$ ) its effect, e.g., in aldol reactions [11]. How can a single enantiomeric resolving agent (ee EuResAg $_{\text {) }}$ enforce its effect?

Single enantiomers are present under different conditions as two conformers. For example, two conformers of enantiomers of benzothiazepine derivatives participate in the crystal structure, imitating the conformers of the more stable racemic crystalline structure $((S, S)-\mathrm{HMB}$ and $(S, R)-\mathrm{HMB})$ (Figure 7) $[15,16]$.<smiles>COc1ccc([C@H]2Sc3ccccc3NC(=O)C2O)cc1</smiles>

$(S, S)-H M B$<smiles>COc1ccc([C@H]2Sc3ccccc3NC(=O)C2O)cc1</smiles>

$(S, R)-\mathrm{HMB}$

Figure 7. Imitative benzothiazepine derivates.

One of the enantiomers ((R)-TOF) of a benzodiazepine derivative (Tofizopam TOF) in chloroform at room temperature including $100 \%$ of the major conformer converts into a mixture of $77.9 \%$ major and $21.8 \%$ minor conformer in $48 \mathrm{~h}$. However, racemic Tofisopam immediately forms two conformers upon dissolution (Figure 8) [17].<smiles>CCc1c(C)nnc(-c2cc(OC)c(OC)cc2-c2ccc(OC)c(OC)c2)c1C</smiles>

(R)-TOF major $77.9 \%$<smiles>CCc1nnc(-c2ccc(OC)c(OC)c2)c2cc(OC)c(OC)cc12</smiles>

(R)-TOF minor $21.8 \%$

Figure 8. The conversion of the conformers of $(R)$-TOF.

It can be interpreted that the two conformers of the single enantiomer are formed immediately in the presence of another chiral molecule.

The single enantiomeric resolving agent is also involved in the crystalline structure of the diastereomeric salt-formed with the enantiomer of the racemic compound-with its two conformers (in a ratio of 41/59), e.g., when reacting (1-hydroxy-2-cyclopentenyl)acetic acid (PGL) with racemic phenylethylamine (PhEA) (Figure 9) [18].

Thus, under the conditions of the crystallization of the diastereomeric salt, ee Dia $_{\text {depends on }}$ either the eutectic composition of the racemic compound (ee $\mathrm{EuRac}_{\text {) }}$ or the eutectic composition of the enantiomeric mixtures of the single enantiomeric resolving agent ( $e_{\text {EuResAg }}$ ) reacting with its two conformers. However, this means that the ratio of the conformers depends on the eutectic composition.

Koshima described that the enantiomers of sodium ammonium tartrate from Pasteur's enantiomeric separation (1848) are formed by crystallization of $\mathrm{M}$ and $\mathrm{P}$ helical double-helix associations (mirror-image crystals containing pure enantiomers) from the conglomerate forming racemic solution $[19,20]$. 


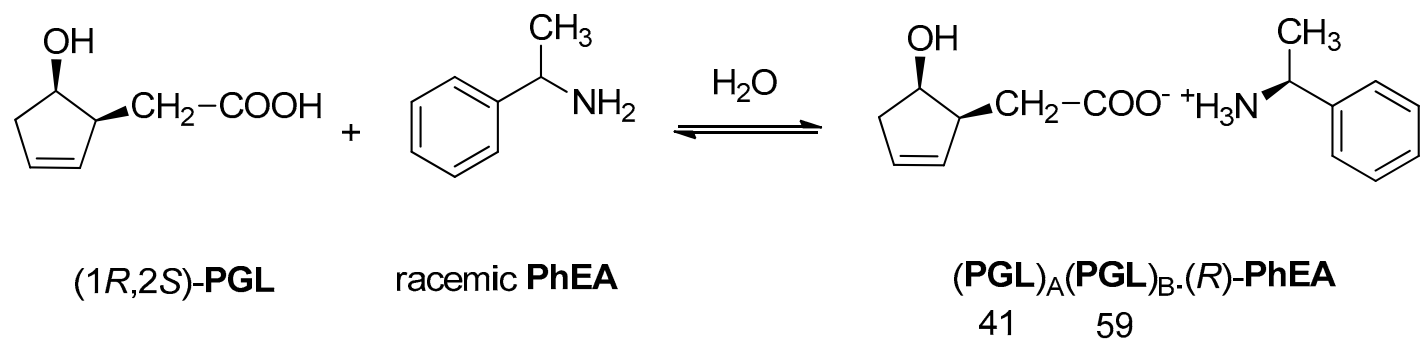

Figure 9. Diastereomeric salt formation with both conformers.

\section{Solvent and Time Dependence of Diastereomeric Mixture Separation by the Effect of the Eutectic Composition}

The following are examples of the effect of the eutectic of the racemic compound and the resolving agent in different solvents with different crystallization times [5,12,21-23]. The diastereomers were separated in each case based on their distribution between the two phases.

\subsection{Role of the Solvent-The Effect of the Eutectic Composition}

Beside the effect of the eutectic composition, the role of the applied solvent can also be observed. For example, in case of the resolution of the intermediate of Flumequin (FTHQ) with di-p-toluyl- $(R, R)$-tartaric acid (DPTA), the composition of the precipitated diastereomer could be influenced by the modification of the solvent. At the same time, in both presented solvents the enantiomeric ratio of the FTHQ enantiomer, separated from its DPTA-salt, corresponded well to the eutectic composition of the FTHQ enantiomeric mixture (ee $\mathrm{EuFTHQ}_{2} \sim \mathrm{ee}_{\mathrm{Dia}}$ ) (Figure 10) [24].

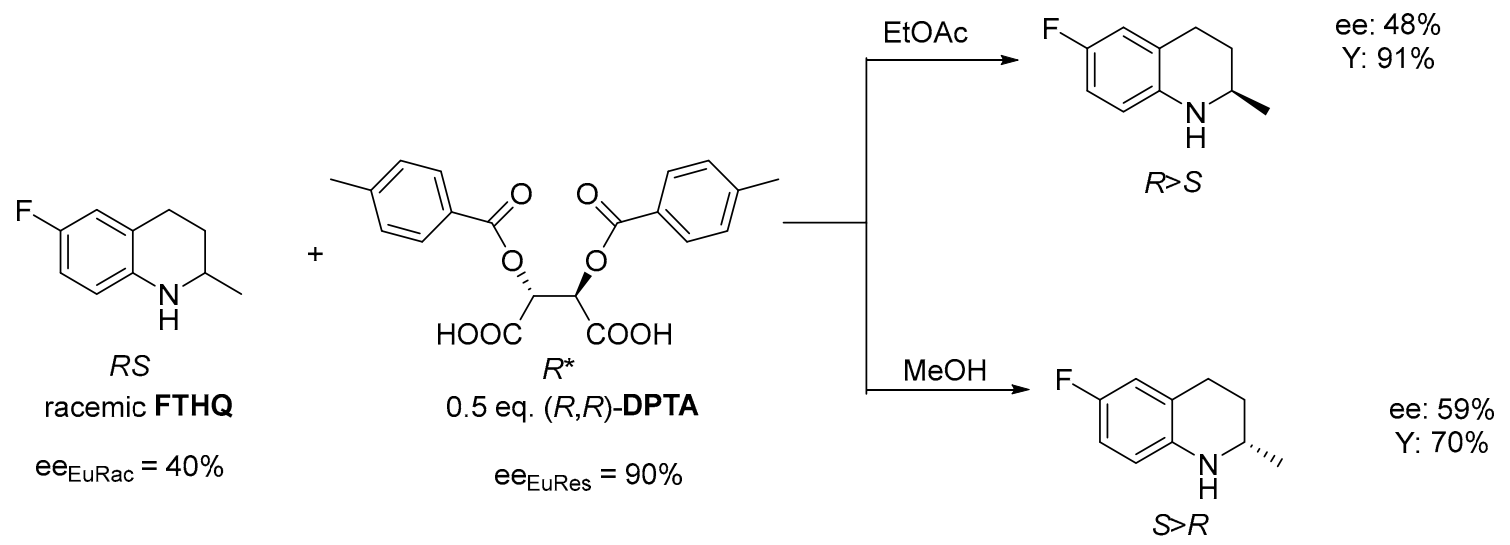

Figure 10. The composition of the diasteromer can be influenced and predetermined by the variation of the solvent.

\subsection{Role of the Crystallization Time-The Effect of Kinetic and Thermodynamic Control on the} Eutectic Composition

In case of the presented resolution, the effect of time could also be observed. Although, by prolonging the crystallization time, the composition of the precipitated diastereomer changed. In both cases of kinetic and thermodynamic control, the eutectic composition of the racemic compound $\left(e_{E u R a c}\right)$ is determinant in the formation of the stoichiometry of the diastereomer (Figure 11) [13]. Thus, the eutectic composition of the racemic compound participates in the formation of the diastereomeric salt $\left(\mathrm{ee}_{\mathrm{EuRac}} \sim \mathrm{ee}_{\mathrm{Dia}}\right)$. 

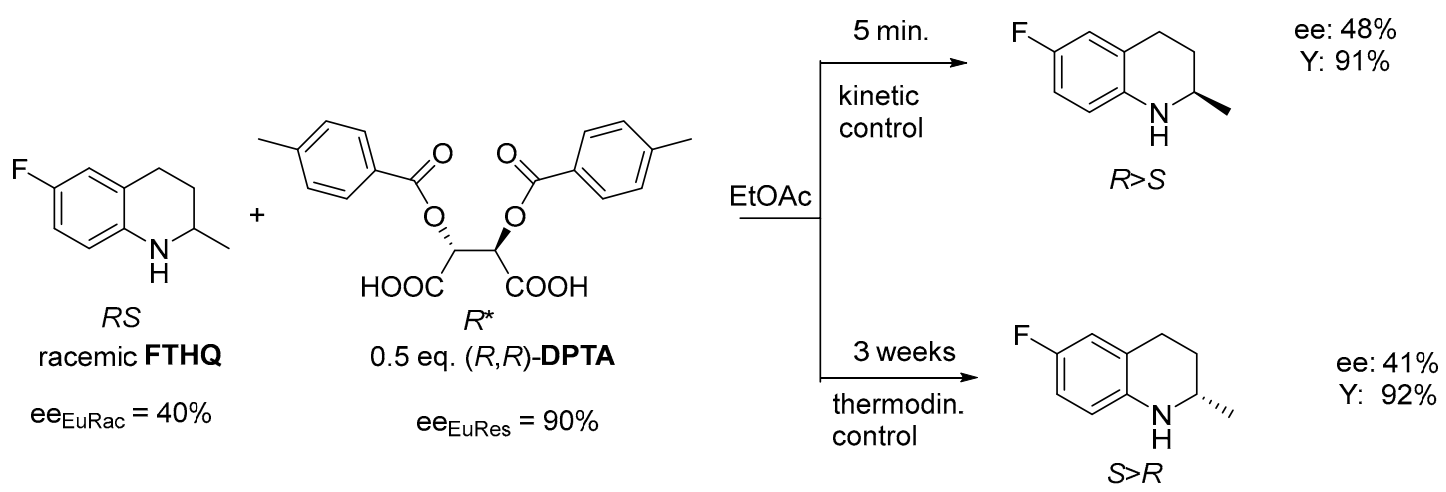

Figure 11. The enantiomeric mixture, taking part in the formation of the diastereomer present in the crystalline phase, alters in the function of the crystallization time.

\subsection{When the ee $e_{E u R e s A g} \sim e e_{D i a} /$ Determinant Role of the Kinetic Control}

In the followings, two resolutions confirming the memory of the resolving agent are presented. In the first one, the resolving agent determines the kinetic control (Figure 12) [25].

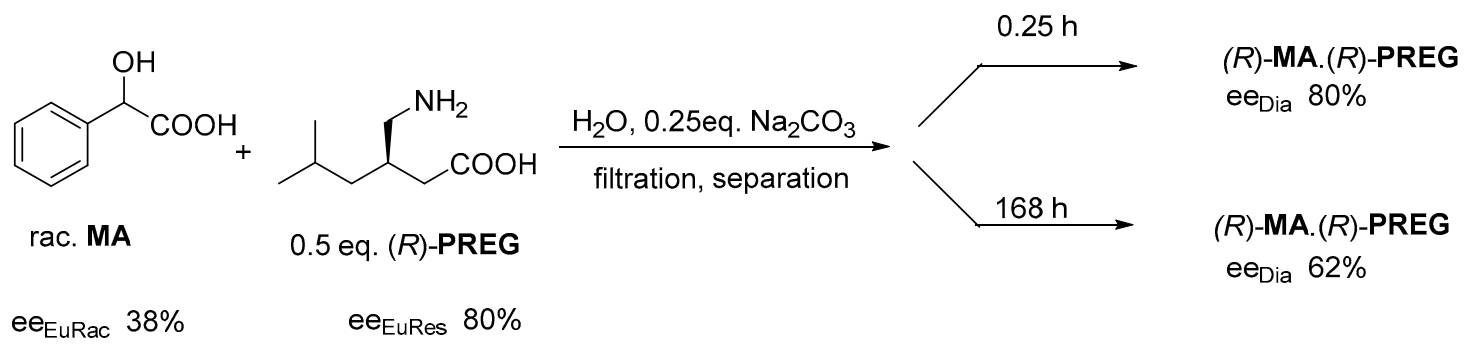

Figure 12. The kinetic control is determined by the resolving agent.

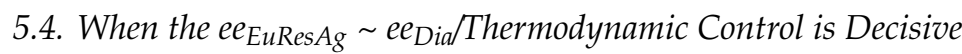

In the second case, the thermodynamic control (Figure 13) is vindicated by the eutectic composition of the enantiomeric mixtures of the racemic compound [25].

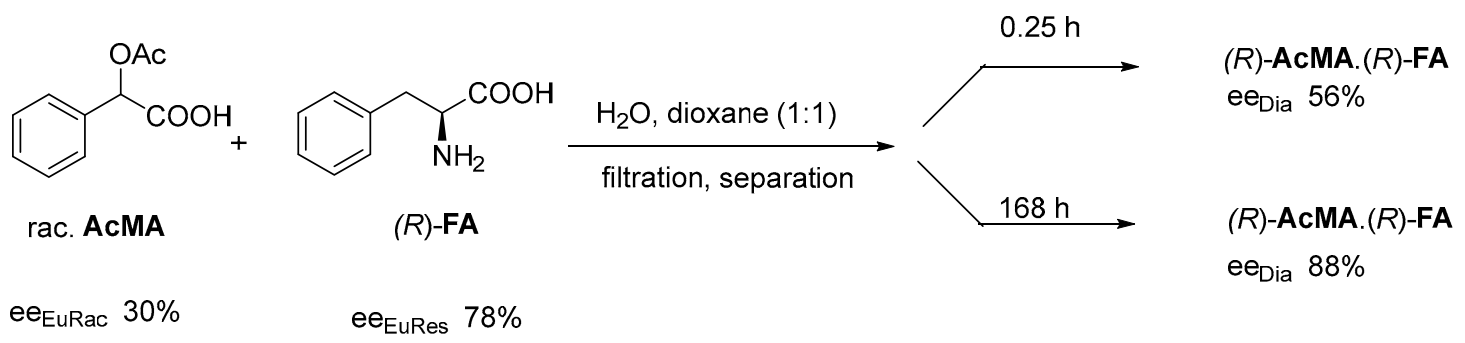

Figure 13. The thermodynamic control is determined by the racemic compound.

\section{Conclusions}

Based on others $[19,20,26]$ and our own experiments $[27,28]$, during the crystallization of molecules, the formation of mirror crystals from solutions of achiral and chiral molecules should be interpreted as behaving as coded robots. In each case, they form supramolecular and helical associations in their solutions. In the case of achiral molecules, the associates with $\mathrm{M}$ and $\mathrm{P}$ helicity are formed in the same amount $(\mathrm{M} \sim \mathrm{P})$. However, for chiral molecules, the $\mathrm{M}$ and $\mathrm{P}$ helicity associates are a function of the eutectic composition of the corresponding enantiomeric mixture, where $\mathrm{M} \neq \mathrm{P}$.

These $\mathrm{M}$ and $\mathrm{P}$ ratios, in addition to the self-disproportionation of enantiomers (SDE) [29-33], validate their effect when the racemic compound is reacted with the resolving agent, and this is why 
the eutectic composition of the racemic compound or the resolving agent occurs in the crystalline diastereomeric salt, depending on which eutectic composition is predominant under the given circumstances. Thus, each chiral molecule reacts with at least two conformers with different degrees of $\mathrm{M}$ and $\mathrm{P}$ helicity.

The code of behavior of molecules validates the combined effect of their configuration, charge distribution, constituent atoms, bonds, flexibility, and asymmetry.

Author Contributions: E.P., D.F.B. and E.F. wrote the paper together, and it is based on the own experimental results. All authors have read and agreed to the published version of the manuscript.

Funding: This work was supported by the National Research, Development and Innovation Office-NKFIH through OTKA grants 124180

Conflicts of Interest: The authors declare no conflict of interest.

\section{References}

1. Girard, C.; Kagan, H.B. Nonlinear Effects in Asymmetric Synthesis and Stereoselective Reactions: Ten Years of Investigation. Angew. Chem. Int. Ed. 1998, 37, 2922-2959. [CrossRef]

2. Soloshonok, V.A. Remarkable amplification of the self-disproportionation of enantiomers on achiral-phase chromatography columns. Angew. Chem. Int. Ed. 2006, 45, 766-769. [CrossRef] [PubMed]

3. Pavlov, V.; Pavlova, T.N. Paradoxes of symmetry: Homochirality, cryptochiral reactions, chiral field, memory, and induction, chiral and racemic environment. Curr. Org. Chem. 2017, 21, 872-888. [CrossRef]

4. Pálovics, E.; Schindler, J.; Faigl, F.; Fogassy, E. Physical Separations: Behavior of Structurally Similar Molecules in the Resolution Processes. In Comprehensive Chirality; Carreira, E.M., Yamamoto, H., Eds.; Elsevier Sciences: Amsterdam, The Netherlands, 2012; Volume 8, pp. 91-95.

5. Pálovics, E.; Faigl, F.; Fogassy, E. Separation of the Mixtures of Chiral Compounds by Crystallization. In Advances in Crystallization Processes; Mastai, Y., Ed.; InTech: London, UK, 2012; pp. 1-37.

6. Roozeboom, H.W.B. Löslichkeit und Schmelzpunkt als Kriterien für racemische Verbindungen, pseudoracemische Mischkrystalle und inaktive Konglomerate. Z. Phys. Chem. 1899, 28, 494-517. [CrossRef]

7. Jacques, J.; Wilen, S.H.; Collet, A. Enantiomers, Racemates and Resolution; Wiley-Interf.: New York, NY, USA, 1881.

8. Fogassy, E.; Faigl, F.; Ács, M. Selective reactions of enantiomeric-mixtures. Tetrahedron Lett. 1981, 22, 3093-3096. [CrossRef]

9. Pasteur, L. Memoires sur la relation qui peut exister entre la forme crystalline et al composition chimique, et sur la cause de la polarization rotatoire. Acad. Sci. 1848, 26, 535-538.

10. Klussmann, M.; Izumi White, A.J.P.; Armstrong, A.; Blackmod, D.G. Emergence of solution-phase homochirality via crystal engineering of amino acid. J. Am. Chem. Soc. 2007, 129, 7657-7660. [CrossRef]

11. Klussmann, M.; Iwamura, H.; Mathew, S.P.; Wells, D.H.; Pandya, U.; Armstrong, A.; Blackmond, D.G. Thermodynamic control of asymmetric amplification in amino acid catalysis. Nature 2006, 441, 621-623. [CrossRef]

12. Faigl, F.; Fogassy, E.; Nógrádi, M.; Pálovics, E.; Schindler, J. Separation of non-racemic mixtures of enantiomers: An essential part of optical resolution. Org. Biomol. Chem. 2010, 8, 947-959. [CrossRef]

13. Bálint, J.; Egri, G.; Kiss, V.; Gajary, A.; Juvancz, Z.; Fogassy, E. Unusual phenomena during the resolution of 6-fluoro-2-methyl-1,2,3,4-tetrahydroquinoline (FTHQ): Thermodynamic-kinetic control. Tetrah. Asymmetry 2002, 12, 3435-3439. [CrossRef]

14. Pálovics, E.; Szeleczky, Z.; Bagi, P.; Faigl, F.; Fogassy, E. Regularities between Separations of Enantiomeric and Diastereoisomeric Mixtures. Prediction of the Efficiency of Diastereomeric/ Enantiomeric Separations on the Basis of Behaviour of Enantiomeric Mixtures. Period. Polytech. Chem. Eng. 2015, 59, 26-37. [CrossRef]

15. Marthi, K.; Larsen, S.; Ács, M.; Jászay, Z.; Fogassy, E. Enantiomer associations in the crystal structures of racemic and (2S,3R)-(-)-3-hydroxy-2-(4-methoxyphenyl)-2,3-dihydro-1,5-benzothiazepin-4(5H)-one. Acta. Chem. Scand. 1996, 50, 906-913. [CrossRef]

16. Marthi, K.; Larsen, S.; Ács, M.; Fogassy, E. Enantiomer assosiations in the crystal structures of racemic and (2S,3S)-(+)-3-hydroxy-2-(4-methoxyphenyl)-2,3-dihydro-1,5-benzothiazepin-4(5H)-one. J. Mol. Struct. 1996, 374, 347-355. 
17. Bosits, M.H.; Pálovics, E.; Madarász, J.; Fogassy, E. New discoveries in enantiomeric separation of racemic tofisopam Hindawi. J. Chem. 2019, 2019. [CrossRef]

18. Czugler, M.; Csöregh, I.; Kálmán, A.; Faigl, F.; Ács, M. Crystal structures of the diastereomeric salt pair of the prostaglandin intermediate $(1 R, 2 S)-(+)$-cis-2-hydroxycyclopent-4-enylacetic acid with $(S)$ - and (R)-1-phenyl-ethyl-amine. J. Mol. Struct. 1989, 196, 157-170. [CrossRef]

19. Koshima, H.; Matsuura, T.J. Chiral crystallization of achiral organic compounds. Synth. Org. Chem. 1998, 56, 268-279. [CrossRef]

20. Koshima, H.; Nakagawa, T.; Miyamoto, H.; Toda, F. Synthesis, structure, and discrimination of chiral bimolecular crystals by using diphenylacetic acid and aza aromatic compounds. J. Org. Chem. 1997, 62, 6322-6325. [CrossRef]

21. Fogassy, E.; Nogradi, M.; Palovics, E.; Schindler, J. Resolution of enantiomers by non-conventional methods. Synth. Stuttg. 2005, 10, 1555-1568. [CrossRef]

22. Fogassy, E.; Nogradi, M.; Kozma, D.; Egri, G.; Pálovics, E.; Kiss, V. Optical resolution methods. Org. Biomol. Chem. 2006, 4, 3011-3030. [CrossRef]

23. Faigl, F.; Fogassy, E.; Nográdi, M.; Pálovics, E.; Schindler, J. Strategies in optical resolution (a practical guide). Tetrahedron Asymmetry 2008, 4, 519-553. [CrossRef]

24. Szeleczky, Z.; Bagi, P.; Pálovics, E.; Fogassy, E. The effect of the eutectic composition on the outcome of kinetically and thermodinamically controlled resolutios that are based on the formation of diastereomers. Tetrahedron Asymmetry 2015, 26, 377-384. [CrossRef]

25. Viedma, C.; McBride, J.M.; Kahr, B.; Cintas, O. Enantiomer-Specific Oriented Attachment: Formation of Macroscopic Homochiral Chrystal Aggregates from a Racemic System. Angew. Chem. Int. Ed. 2013, 52, 10545-10548. [CrossRef] [PubMed]

26. Pálovics, E.; Fogassy, E. A Presumable Mechanism of the Separation of Diastereomeric and Enantiomeric Mixtures. J. Chromatogr. Sep. Tech. 2017, 8, 391.

27. Pálovics, E. Separation of Mixtures of Chiral Compounds by their Distribution between Different Phases. J. Chromatogr. Sep. Tech. 2019, 10, 422.

28. Oaki, Y.; Imai, H. Stereospecific morphogenesis of aspartic acid helical crystals through molecular recognition. Langmuir 2007, 23, 5466-5470. [CrossRef]

29. Kobayashi, Y.; Kodama, K.; Saigo, K. Supramolecular architecture consisting of an enantiopure amine and an achiral carboxylic acid: Application to the enantioseparation of racemic alcohols. Org. Lett. 2004, 6, 2941-2944. [CrossRef]

30. Kobayashi, Y.; Kodama, K.; Saigo, K. Enantioselective inclusion of chiral alkyl aryl sulfoxides in a supramolecular helical channel consisting of an enantiopure 1,2-amino alcohol and an achiral carboxylic acid. Tetrahedron Asymmetry 2008, 19, 295-301. [CrossRef]

31. Weissbuch, I.; Leiserowitz, L.; Lahav, M. Stochastic "mirror symmetry breaking" via self-assembly reactivity and amplification of chirality: Relevance to abiotic conditions. Top. Curr. Chem. 2005, 259, 123-165.

32. Tamura, R.; Iwama, S.; Gonnade, R.G. Control of polymorphic transition inducing preferential enrichment. Cryst. Eng. Comm. 2011, 13, 5269-5280. [CrossRef]

33. Pálovics, E.; Fogassy, E. Memory of Chiral Molecules Define Their Interactions and the Results of Resolution Processes. Am. J. Chem. Eng. 2018, 6, 65-71. [CrossRef]

(C) 2020 by the authors. Licensee MDPI, Basel, Switzerland. This article is an open access article distributed under the terms and conditions of the Creative Commons Attribution (CC BY) license (http://creativecommons.org/licenses/by/4.0/). 